Nota de investigación

\title{
Características vegetativas de plantas de ajo con síntomas de 'encerado' en Zacatecas
}

\author{
Manuel Reveles-Hernández \\ Rodolfo Velásquez-Valle \\ José Ángel Cid-Ríos \\ Campo Experimental Zacatecas-INIFAP. Carretera Zacatecas-Fresnillo km 24.5, Calera de VR., Zacatecas, \\ México. CP. 98500. \\ ${ }^{\S}$ Autor para correspondencia: velasquez.rodolfo@inifap.gob.mx.
}

\section{Resumen}

El estado de Zacatecas es el principal productor de ajo en México. Recientemente se reportó la presencia de Candidatus Phytoplasma trifolii en esta región afectando a las plantas de ajo que mostraban síntomas como enanismo, hojas brillantes y poca o ninguna diferenciación de dientes a las cuales se les conoce como ajos 'encerados'. Considerando que no existe información acerca del impacto de esta sintomatología en plantas de ajo el propósito de este trabajo fue determinar su efecto sobre características vegetativas de las plantas de cuatro genotipos de ajo (Tigre, Platero, Enc-4 y CH-6). El 'encerado' en plantas de ajo se encontró asociado con pérdidas consistentes en altura de planta y longitud de hojas y en menor grado en peso de hojas y de pseudotallo. El resto de las variables mostró comportamiento errático entre genotipos y fechas de muestreo.

Palabras clave: Candidatus Phytoplasma trifolii, genotipos de ajo, impacto, síntomas.

Recibido: junio de 2021

Aceptado: julio de 2021 
El estado de Zacatecas es el principal productor de ajo (Allium sativum L.) en México, alrededor de 3400 ha se siembran con este bulbo en la entidad que representan $47 \%$ de la superficie y $60 \%$ de la producción nacional (SIACON, 2018). Se han identificado los virus del enanismo amarillo de la cebolla Onion yellow dwarf virus (OYDV), de la franja amarilla del puerro Leek yellow stripe virus (LYSV), latente del shallot Shallot latent virus (SLV), común latente del ajo Garlic common latent virus (GarCLV) y jaspeado del tabaco Tobacco etch virus (TEV) en plantas con síntomas como mosaico difuso y deformaciones de la vena central (Velásquez-Valle et al., 2010a).

Desde 2010 se reportó la presencia de un grupo de síntomas conocidos como ‘encerado' (enanismo, hojas brillantes e inclinadas hacia el suelo y bulbos con escasa o nula diferenciación de dientes) en plantas de ajo cuya incidencia en parcelas comerciales variaba entre 1 y 5\%. Los resultados de Elisa mostraron la presencia del virus mencionados previamente, incluso en plantas aparentemente sanas por lo que no fue posible concluir acerca de la asociación entre esos virus y la sintomatología (Velásquez-Valle et al., 2010b). Recientemente se reportó la presencia de Candidatus Phytoplasma trifolii (16SrVI) (CPt) asociada con plantas de ajo colectadas en la misma región (Fresnillo, Zacatecas) y que mostraban la sintomatología previamente descrita (Reveles-Torres et al., 2018).

La infección de plantas de ajo por fitoplasmas ha sido mencionada en Argentina y Estados Unidos de América (Galdeano et al., 2009; Mollov et al., 2014), aunque la sintomatología exhibida no concuerda completamente con la observada en Zacatecas. Actualmente, no existe una estimación del impacto de esta sintomatología sobre el desarrollo de las plantas de ajo por lo que el objetivo del presente trabajo consistió en determinar el efecto de la sintomatología conocida como 'encerado' en características vegetativas de plantas de genotipos de ajo.

El trabajo se realizó en la parcela del Campo Experimental Zacatecas del Instituto Nacional de Investigaciones Forestales, Agrícolas y Pecuarias (INIFAP), en Calera de V. R., Zacatecas, México. La parcela se estableció el 22 de noviembre de 2018 y recibió el manejo recomendado por el Campo Experimental Zacatecas (Reveles-Hernández et al., 2009), de esta parcela se extrajeron 10 plantas con síntomas de 'encerado' (S) y 10 plantas aparentemente sanas (AS) en cada uno de cuatro genotipos de ajo (Tigre, Ch-6, Platero y Enc-4) sembrados en camas con cuatro hileras de plantas, el muestreo se realizó en dos fechas y representativas del desarrollo de las plantas, 14 de marzo y 24 de abril de 2019 (112 y 153 días después de la siembra, que corresponden a las fases de inicio de bulbificación y llenado del bulbo aproximadamente).

A cada planta se le tomaron los siguientes datos: altura $(\mathrm{cm})$, diámetro de cuello $(\mathrm{mm})$, peso $(\mathrm{g})$ y diámetro ecuatorial de bulbo $(\mathrm{mm})$, número de hojas, así como su longitud, ancho $(\mathrm{cm})$ y su peso (g) y el peso del pseudotallo (g). Para comparar la información obtenida con ambos tipos de plantas (AS y S) se utilizó una prueba de parcelas apareadas $(\alpha: 0.05)$.

\section{Tigre}

En ambas fechas de muestreo la altura de planta, longitud de hojas, peso de hojas y peso de pseudotallo de AS fue superior al de S. En las variables diámetro de bulbo, peso de bulbo y número de hojas no se encontró diferencia entre ambos tipos de plantas en las dos fechas de muestreo. En el variable diámetro de cuello las $\mathrm{S}$ resultaron superiores a las AS en ambas fechas de muestreo. El ancho de las hojas resultó favorable a AS en la primera fecha de muestreo, pero no se observó diferencia significativa entre ambos tipos de plantas en el segundo muestreo (Cuadros 1 y 2). 
Cuadro 1. Comparación de valores medios de características de plantas de cuatro genotipos de ajo aparentemente sanas (AS) y con síntomas asociados al 'encerado' (S) en Zacatecas, México. Primer muestreo.

\begin{tabular}{|c|c|c|c|c|c|c|c|c|}
\hline \multirow{2}{*}{ Característica } & \multicolumn{2}{|c|}{ Tigre } & \multicolumn{2}{|c|}{ Ch-6 } & \multicolumn{2}{|c|}{ Platero } & \multicolumn{2}{|c|}{ Enc-4 } \\
\hline & $\mathrm{AS}^{1}$ & $S^{2}$ & AS & $\mathrm{S}$ & AS & $\mathrm{S}$ & AS & $\mathrm{S}$ \\
\hline Altura (cm) & 33.3 & $13.9^{*}$ & 32.5 & $17.1^{*}$ & 32.3 & $17.7^{*}$ & 33.6 & $17.1^{*}$ \\
\hline Cuello $^{3}(\mathrm{~mm})$ & 1.2 & $1.3^{*}$ & 1.22 & $1.6^{*}$ & 1.3 & $1.7 \mathrm{~ns}$ & 1.4 & $1.8^{*}$ \\
\hline $\mathrm{Bulbo}^{4}(\mathrm{~mm})$ & 2.2 & $2.1 \mathrm{~ns}$ & 2.1 & $2.8^{*}$ & 2.3 & $2.9^{*}$ & 2.2 & $2.7^{*}$ \\
\hline Peso bulbo (g) & 11 & $8.9 \mathrm{~ns}$ & 10.2 & $13.7^{*}$ & 12.5 & $15.8 \mathrm{~ns}$ & 11.5 & $14 \mathrm{~ns}$ \\
\hline No. de hojas & 5.7 & $4.9 \mathrm{~ns}$ & 5.8 & $5^{*}$ & 5.9 & $5.7 \mathrm{~ns}$ & 6.2 & $5.8 \mathrm{~ns}$ \\
\hline Long. hojas (cm) & 33.7 & $18.8^{*}$ & 28.8 & $17.1^{*}$ & 31.6 & $20^{*}$ & 31.5 & $19.1^{*}$ \\
\hline Ancho hojas (cm) & 2 & $1.4^{*}$ & 2.1 & $1.7^{*}$ & 2.1 & $1.9 \mathrm{~ns}$ & 2.1 & $1.9^{*}$ \\
\hline Peso hojas (g) & 16.4 & $4.6^{*}$ & 16.8 & $6.3^{*}$ & 20 & $10.5^{*}$ & 21.4 & $10^{*}$ \\
\hline Pseudotallo (g) & 8.9 & $3.1^{*}$ & 8.7 & $4.6^{*}$ & 9.2 & $6.5 \mathrm{~ns}$ & 10.9 & $7.2^{*}$ \\
\hline
\end{tabular}

${ }^{1}=$ aparentemente sana; ${ }^{2}=$ intomática a 'encerado'; ${ }^{3,4}=$ diámetro; ns= diferencia no significativa; ${ }^{*}=$ diferencia significativa.

Cuadro 2. Comparación de valores medios de características de plantas de cuatro genotipos de ajo aparentemente sanas (AS) y con síntomas asociados al 'encerado' (S) en Zacatecas, México. Segundo muestreo.

\begin{tabular}{|c|c|c|c|c|c|c|c|c|}
\hline \multirow{2}{*}{ Característica } & \multicolumn{2}{|c|}{ Tigre } & \multicolumn{2}{|c|}{ Ch-6 } & \multicolumn{2}{|c|}{ Platero } & \multicolumn{2}{|c|}{ Enc-4 } \\
\hline & $\mathrm{AS}^{1}$ & $S^{2}$ & AS & $\mathrm{S}$ & AS & S & AS & $\mathrm{S}$ \\
\hline Altura $(\mathrm{cm})$ & 64.7 & $25.2^{*}$ & 70 & $30.8^{*}$ & 63.9 & $26.5^{*}$ & 59.7 & $28.1^{*}$ \\
\hline Cuello $^{3}(\mathrm{~mm})$ & 1.4 & $1.8^{*}$ & 1.7 & $2 \mathrm{~ns}$ & 1.5 & $1.9 \mathrm{~ns}$ & 1.3 & $1.6 \mathrm{~ns}$ \\
\hline $\mathrm{Bulbo}^{4}(\mathrm{~mm})$ & 2.9 & $3.2 \mathrm{~ns}$ & 3.6 & $3.7 \mathrm{~ns}$ & 3.4 & $3.6 \mathrm{~ns}$ & 3.5 & $3.4 \mathrm{~ns}$ \\
\hline Peso bulbo (g) & 25.3 & $26.4 \mathrm{~ns}$ & 39.3 & $35.8 \mathrm{~ns}$ & 35.6 & $34.5 \mathrm{~ns}$ & 33.6 & $33.7 \mathrm{~ns}$ \\
\hline No. de hojas & 6.8 & $6.4 \mathrm{~ns}$ & 7.3 & $5.9^{*}$ & 7 & $7.2 \mathrm{~ns}$ & 7.6 & $7 \mathrm{~ns}$ \\
\hline Long. hojas $(\mathrm{cm})$ & 41.7 & $24^{*}$ & 46 & $26.6^{*}$ & 39.6 & $26.8^{*}$ & 36.9 & $25.6^{*}$ \\
\hline Ancho hojas $(\mathrm{cm})$ & 2.1 & $1.9 \mathrm{~ns}$ & 2.5 & $2.2 \mathrm{~ns}$ & 2.2 & $2.1 \mathrm{~ns}$ & 2 & $1.8 \mathrm{~ns}$ \\
\hline Peso hojas (g) & 30.6 & $18.5^{*}$ & 44.1 & $20.6^{*}$ & 32.4 & $23.5 \mathrm{~ns}$ & 29 & $22 \mathrm{~ns}$ \\
\hline Pseudotallo (g) & 26.2 & $15.4^{*}$ & 37.8 & $19.8^{*}$ & 29 & $16.4^{*}$ & 23.8 & $15.4^{*}$ \\
\hline
\end{tabular}

${ }^{1}=$ aparentemente sana; ${ }^{2}=$ sintomática a 'encerado'; ${ }^{3,4}=$ diámetro; $n s=$ diferencia no significativa; ${ }^{*}=$ diferencia significativa

\section{Ch-6}

Los valores medios de las variables altura de planta, número de hojas, longitud de hojas, peso de hojas y peso de pseudotallo en las AS resultaron mayores que los de S en ambas fechas de muestreo. Las variables diámetro de cuello, diámetro de bulbo, peso de bulbo y ancho de hojas fueron mayores en $\mathrm{S}$ durante el primer muestreo, pero no mostraron diferencia significativa en el segundo muestreo (Cuadros 1 y 2). 


\section{Platero}

Solamente las variables altura de planta y longitud de hojas fueron superiores en AS en ambas fechas de muestreo. No se detectaron diferencias en los valores de diámetro de cuello, peso de bulbo, número de hojas y ancho de hojas de plantas enfermas y aparentemente sanas en las dos fechas de muestreo. El diámetro de bulbo fue mayor en $\mathrm{S}$ en la primera fecha de muestreo pero no presentó diferencia entre ambos tipos de planta en la segunda fecha de muestreo. El peso de hojas en el primer muestreo fue favorable a AS mientras que en el segundo muestreo no sé detecto diferencia, una situación inversa ocurrió con el peso del pseudotallo que durante el primer muestreo no manifestó diferencias entre ambos tipos de planta, pero resultó superior en AS durante el segundo muestreo (Cuadros 1 y 2).

\section{Enc-4}

Las variables altura de planta, longitud de hojas y peso de pseudotallo en AS fueron superiores a las de $\mathrm{S}$ en ambas fechas de muestreo. Los valores de peso de bulbo y número de hojas resultaron similares entre ambos tipos de plantas y fechas de muestreo. Las variables ancho de hojas y peso de hojas fueron superiores en AS durante el primer muestreo, pero no mostraron diferencias en el segundo muestreo. Los valores de diámetro de cuello y diámetro de bulbo fueron mayores en $\mathrm{S}$ durante el primer muestreo, pero no mostraron diferencia en el segundo muestreo (Cuadros 1 y 2).

Los fitoplasmas son microorganismos cuyo habitat se restringe a los tejidos del floema de sus hospederos debido a su alto contenido de fructuosa y glucosa lo que provoca un desbalance fisiológico que conduce a la inducción de una amplia gama de síntomas que apuntan hacia una alteración en el contenido del floema y pérdida del balance hormonal (Arismendi et al., 2010). Algunos de los síntomas observados en las plantas de ajo en Zacatecas como enanismo, hojas cortas y engrosamiento del pseudotallo y bulbo podrían ser resultado directo de la infección por CPt.

Uno de los síntomas que caracterizan a la enfermedad es el engrosamiento de cuello y bulbo, ambos síntomas se presentaron en los cuatro genotipos de ajo estudiados. Durante el primer muestreo los valores medios de esas variables fueron significativamente mayores en plantas de Tigre, Ch-6 y Enc-4 para diámetro de cuello y para Ch-6, Platero y Enc-4 para diámetro de bulbo. Durante el segundo muestreo solamente el diámetro de cuello en las $\mathrm{S}$ del genotipo Tigre superaba a las de AS. Para los cuatro genotipos y en ambas fechas de muestreo los valores medios de altura de planta y longitud de hojas de AS fueron consistentemente superiores a los de $\mathrm{S}$ en los cuatro genotipos en ambas fechas de muestreo. El enanismo en plantas de ajo infectadas por fitoplasmas ha sido previamente mencionado por Mollov et al. (2014).

La pérdida de altura de $\mathrm{S}$ fue consistente en ambos muestreos para las $\mathrm{S}$ en los cuatro genotipos. En la primera fecha de muestreo, el porcentaje de reducción en esta variable osciló entre 50.9 (Enc- 4, primer muestreo) y 61.1 (Tigre, segundo muestreo). Durante el segundo muestreo estos porcentajes aumentaron marginalmente para todos los genotipos, aunque Enc4 y Platero fueron las que resultaron con menor (2\%) y mayor (3.7\%) incremento respectivamente (Cuadro 3 ). 
Cuadro 3. Características de plantas de cuatro genotipos de ajo con síntomas de 'encerado' durante 2018 en Zacatecas, México.

\begin{tabular}{|c|c|c|c|c|c|c|c|c|}
\hline \multirow{2}{*}{ Característica } & \multicolumn{2}{|c|}{ Tigre } & \multicolumn{2}{|c|}{ Ch -6} & \multicolumn{2}{|c|}{ Platero } & \multicolumn{2}{|c|}{ Enc - 4} \\
\hline & 14 marzo & 24 abril & 14 marzo & 24 abril & 14 marzo & 24 abril & 14 marzo & 24 abril \\
\hline Altura (cm) & $-58.2^{1}$ & -61.1 & -52.6 & -56 & -54.8 & -58.5 & -50.9 & -52.9 \\
\hline Cuello $^{2}$ (mm) & 5.7 & 32.3 & 35.2 & 0 & 0 & 0 & 28.6 & 0 \\
\hline $\mathrm{Bulbo}^{3}(\mathrm{~mm})$ & 0 & 0 & 33.3 & 0 & 26.1 & 0 & 22.7 & 0 \\
\hline Peso bulbo (g) & 0 & 0 & 34.3 & 0 & 0 & 0 & 0 & 0 \\
\hline Número de hojas & 0 & 0 & -13.8 & -19.2 & 0 & 0 & 0 & 0 \\
\hline Long. hojas $(\mathrm{cm})$ & -44.2 & -42.4 & -40.6 & -42.2 & -36.7 & -32.3 & -39.4 & -30.6 \\
\hline Ancho hojas $(\mathrm{cm})$ & -30 & 0 & -19 & 0 & 0 & 0 & -9.5 & 0 \\
\hline Hojas (g) & -71.9 & -39.5 & -62.5 & -53.3 & -47.5 & -27.5 & -53.3 & -24.1 \\
\hline Pseudotallo (g) & -65.2 & -41.2 & -47.1 & -47.6 & 0 & -43.4 & -33.9 & -35.3 \\
\hline
\end{tabular}

${ }^{1}=$ medias con signo negativo indican la pérdida $(\%)$ en una variable dada para plantas con síntomas de 'encerado', medias con número positivos indican el porcentaje de ganancia en una variable dada para plantas enfermas y medias en cero indican diferencia no significativa entre plantas aparentemente sanas y enfermas. ${ }^{2,3}=$ diámetro.

La longitud de las hojas de AS fue mayor que la de $\mathrm{S}$ en todos los casos (genotipos o fecha de muestreo), la pérdida de longitud de hojas, en términos de porcentaje, fue de 30.6 (Enc-4, segundo muestreo) a $44.2 \%$ (Tigre, primer muestreo). Las variables peso de hojas y peso de pseudotallo mostraron parcialmente la misma tendencia: en la mayoría de los casos los valores de AS fueron mayores que los de $\mathrm{S}$. Las pérdidas en esas variables fueron severas, especialmente para el genotipo Tigre en el primer muestreo donde las $\mathrm{S}$ experimentaron una reducción de 71.9 y $65.2 \%$ en el peso de hojas y pseudotallo, respectivamente (Cuadro 3).

Solamente en tres genotipos los valores de ancho de hojas de AS fueron superiores a los de $\mathrm{S}$ conduciendo a pérdidas variables entre 9.5 (Enc-4, primer muestreo) y 30\% (Tigre, primer muestreo), en el resto de los genotipos no se encontraron diferencias entre AS y S o entre fechas de muestreo. Notablemente, y en ambos muestreos el número de hojas en AS fue mayor que en $\mathrm{S}$ en el genotipo $\mathrm{CH}-6$. La pérdida en número de hojas en $\mathrm{S}$ fue de 13.8 y $19.2 \%$ para el primero y segundo muestreo respectivamente (Cuadro 3).

Las variables de diámetro de cuello, diámetro de bulbo y peso de bulbo expresaron diferencias a favor de S, especialmente en el primer muestreo. Para el genotipo Tigre los valores de la variable diámetro de cuello favorecieron a $\mathrm{S}$ en ambas fechas de muestreo lo cual significó que el diámetro de sus bulbos fuera 5.7 y $32.3 \%$ más grande que el de AS, en el primero y segundo muestreo respectivamente (Cuadro 3). Lo anterior contrasta con lo mencionado por Mollov et al. (2014), quienes señalan que las plantas de ajo infectadas por fitoplasmas del grupo 16SrI (Aster Yellows) presentaban bulbos de tamaño menor al normal.

\section{Conclusiones}

La sintomatología denominada 'encerado' en cuatro genotipos de ajo se encontró asociada con pérdidas consistentes en altura de planta y longitud de hojas y en menor grado, en peso de hojas y de pseudotallo. El resto de las variables evaluadas mostró un comportamiento errático entre genotipos y fechas de muestreo. 


\section{Literatura citada}

Arismendi, N.; Carrillo, L. I. R. y Andrade, S. N. 2010. Molicutes fitopatógenos transmitidos por insectos: interacciones y efectos en sus vectores. Agro Sur. 38(2):55-67.

Galdeano, E.; Conci, L. R.; González, O.; Paradell, S.; Di Rienzo, J. A.; Nome, C. and Conci, V. C. 2009. Epidemiological aspects of garlic decline disease caused by a phytoplasma in Asiatic and Argentinean garlic cultivars. Australasian Plant Pathol. 38(4):437-443. https://10.1071/AP09019.

Mollov, D.; Lockhart, B.; Saalau-Rojas, E. and Rosen, C. 2014. First report of a 16SrI (Aster Yellows) group phytoplasma on garlic (Allium sativum) in the United States. Plant Dis. 98(3):419-425. Doi.org/10.1094/PDIS-07-13-0689-PDN.

Reveles-Hernández, M.; Velásquez-Valle, R. y Bravo-Lozano, A. G. 2009. Tecnología para cultivar ajo en Zacatecas. Libro Técnico Núm. 11. INIFAP- Campo Experimental Zacatecas. Calera de V. R., Zacatecas, México. 272 p.

Reveles-Torres, L. R.; Velásquez-Valle, R.; Mauricio-Castillo, J. A. and Salas-Muñoz, S. 2018. First report of "Candidatus Phytoplasma trifolii"-related strain associated with a new disease on garlic in Zacatecas, México. Plant Dis. 102(12):2636.

SIACON. 2018. Estadística agrícola del año 2018. https://www.gob.mx/siap/documentos/siaconng-161430.

Velásquez-Valle, R.; Chew-Madinaveitia, Y. I.; Amador-Ramírez, M. D. y Reveles-Hernández, M. 2010a. Presencia de virus en el cultivo de ajo (Allium sativum L.) en Zacatecas, México. Rev. Mex. Fitopatol. 28(2):135-143.

Velásquez-Valle, R.; Chew-Madinaveitia, Y. I.; Reveles-Hernández, M. y Amador-Ramírez, M. D. 2010b. Enfermedades provocadas por virus en el cultivo de ajo en el norte centro de México. Folleto técnico núm. 22. INIFAP-Campo Experimental Zacatecas. Calera de V. R. Zacatecas, México. 61 p. 